\title{
SYNCHRONOUS DYNAMIC TRACKING CONTROL DESIGN FOR THEDIAMOND MULTI-WIRE SAWING SYSTEM
}

\author{
Chih-Cheng Peng ${ }^{1}$, Shiaw-Wu Chen ${ }^{2}$, Thong-ShingHwang ${ }^{3}$ \\ ${ }^{1}$ Graduate Institute of Electrical and Communications Engineering, Feng Chia University, Taiwan, R.O.C \\ ${ }^{2}$ Graduate Institute of Automatic Control Engineering, Feng Chia University, Taiwan, R.O.C \\ ${ }^{3}$ Graduate Institute of Automatic Control Engineering, Feng Chia University, Taiwan, R.O.C
}

\begin{abstract}
The purpose of this paper is to investigate the effect of control factors on the ablation characteristics by using Taguchi method and adopt self-tuning fuzzy-PID controller design to tune the moving-wire velocity. The characteristics of the sawing system include ingot profile variance and cutting rate. The optimal ablation parameters are tension force, wire velocity, cutting force, width of the kerf. The $L_{9}\left(3^{4}\right)$ orthogonal array, signal-to-noise ( $\left.S / N\right)$ ratio and analysis of variance (ANOVA) are employed to analyze the effect of these ablation parameters. Using the optimal ablation parameters, we accomplish the diamond multi-wire sawing (DMWS) high-speed control and synchronous dynamic tracking of the main roller under the moving wire bow angle holding. The simulation results show that the cutting rate is direct proportional to moving wire speed and cutting force. Also, the passive main roller can almost track the active main roller synchronously and dynamically under the sustained bow angle within $5.7^{\circ}$ in 7 forward and 5 backward wire-moving.
\end{abstract}

Keyword: Taguchi Method, Self-Tuning Fuzzy-PID, Diamond Multi-Wire Sawing, Synchronous Dynamic Tracking

\section{INTRODUCTION}

From the literatures we can find till now, the research of the diamond multi-wire sawing system is only limited to simulation and analysis of the process modeling and monitoring [1 3]. Still not yet integrate the slicing dynamic model and machining parameters to the slicing control system design.

In this paper, firstly we use Taguchi experimental design method to find the optimized slicing parameters in order that the diamond multi-wire slicing performance can be optimized at the same time regarding with the maximized wire feed slicing speed and the minimized ingot slicing surface thickness variance. In the meanwhile, we apply these optimized machining parameters as desire tracking input signals to accomplish the design and simulation of synchronous dynamic tracking in the DMWS system.

\section{DMWS DYNAMIC MODEL ANALYSIS}

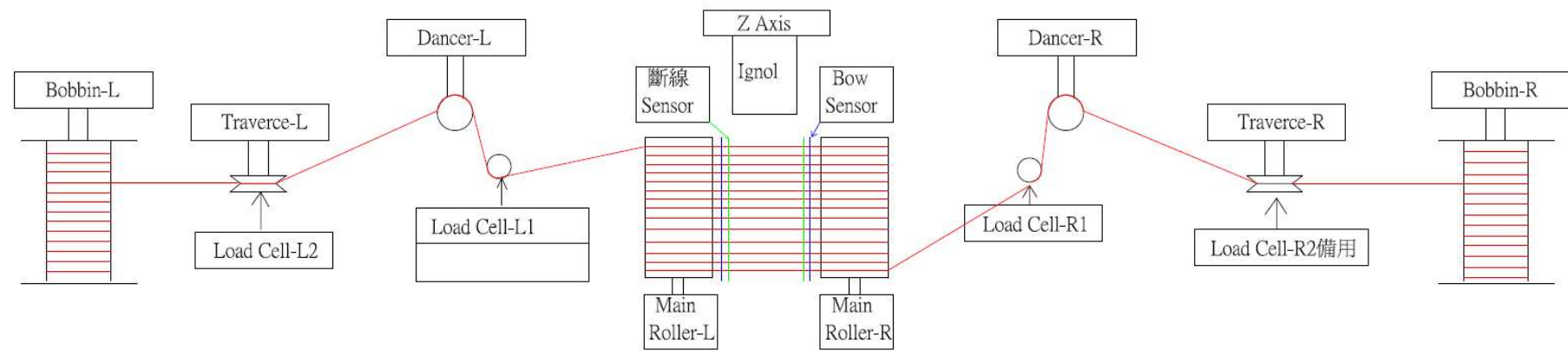

Fig.1 Diamond multi-wire saw slicing system

Fig. 1 is the brief diagram of the diamond multi-wire sawing system, the slicing mechanism formed by the two main spindle rollers performs the slicing machining. This study mainly includes three parts as the dynamic model analysis, slicing machining parameters optimization, and the synchronous dynamic tracking of the main roller under the moving wire bow angle holding.
The slicing dynamic model derived for the diamond multi-wire slicing system is referred to the literature [1], the illustration diagram is Fig.2, $\mathrm{L}$ is the distance between two main spindle rollers, $U$ is the wire feed speed, $F$ is the slicing cutting force. 

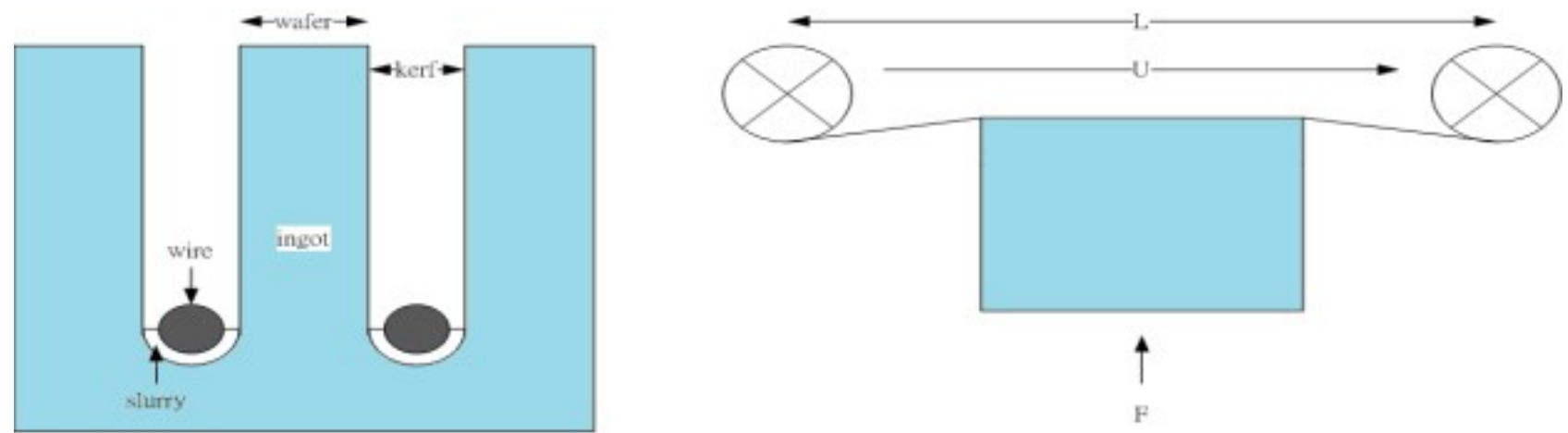

Fig.2 Illustration diagram of wire saw cutting system

While using the Chemical Mechanical Polish (CMP) Method to derive the material removal model, Preston equation is usually used to express CMP removal rate, which is proportional to the vertical cutting force and the moving wire feed speed: $(\Delta w / \Delta t) \propto P(\Delta s / \Delta t)$. Herew is the depth of the surface, $\mathrm{t}$ is the time, $\mathrm{P}$ is the pressure onto ingot, $\Delta s / \Delta t$ is the relative speed between cutting wire and ingot.

From the related study, we can see the material removal rate has very close relationship with gap between the wire and ingot, and the pressure onto the ingot is related to the cutting area width[1]. Suppose the cutting area is the half cylindrical shape, the pressure can be expressed: $P=\frac{F_{p}}{\frac{1}{2} \text { channelcircumference }}=\frac{2 F_{p}}{\pi D_{k}}, D_{k}$ is the cutting area width (wire diameter), $\Delta s / \Delta t$ is the movingwire feed speed, so the cutting speed rate is:

$$
\frac{\Delta w}{\Delta t}=K_{P} \frac{2 F_{P}}{\pi D_{k}} U
$$

$K_{p}$ is Preston coefficient which is an experienced value, it has been proved to be inverse proportional to the Young's modulus of the ingot for fixed abrasive slicing machining. $K_{P}=1 /\left(2 E_{\text {substrate }}\right) \cdot E_{\text {substrate }}$ is the Young's Modulus of the ingot. And the distributed loading force $\left(F_{p}\right)$ on the abrasive is a function of the cutting force as the equation expressed bellow. And the gap between wire and the ingot can be defined as:

$$
F_{P}=F \frac{e^{-h(x, t)}}{\int_{0}^{L} e^{-h(x, t)} d x}, h(x, t)=y(x, t)-w(x, t)
$$

The illustrated diagram just like the Fig.3:

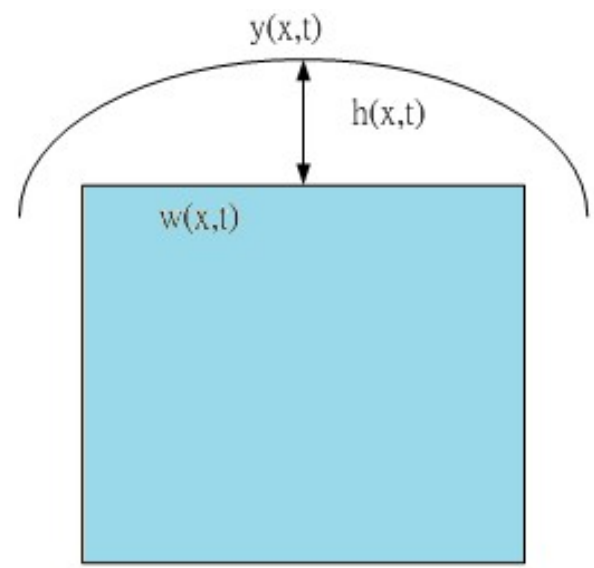

Fig.3 The illustrated diagram of the gap between wire and ingot

According to the former study, the ingot contour can be developed very slowly. And new grinding liquid thickness $h(x, t)$ and $F_{P}$ can be generated iteratively while passing each time interval. Under such cycle we can complete the dynamic iteration equation as follows:

$$
W_{n+1}(x, t)=W_{n}(x, t)+\frac{\Delta w}{\Delta t} \cdot \Delta t
$$

\section{TAGUCHI EXPERIMENTAL DESIGN FOR DMWS SYSTEM}

\subsection{The Taguchi Experimental Method}

The so called optimized design of the slicing system here is to design the optimized control factors to cause the slicing rate to be maximal or the slicing contour variance to be minimal or both considered. The Taguchi method is a kind of robust design using orthogonal array matrix experiments.

The performance can be evaluated by signal/noise ratio, including 3 kinds of signal/noise ratio as follows:

1. The signal/noise ratio of the cutting speed: The cutting speed is expected to be larger.

2. The signal/noise ratio of the ingot slicing contour variance: It is expected to be smaller.

3. The hybrid signal/noise ratio of the cutting speed rate and the ingot slicing contour variance. 
$\eta_{i}=10 \times \log _{10}\left[\frac{\sum_{k=1}^{60}\left(\frac{\Delta w}{\Delta t}\right)^{2}}{\sum_{k=1}^{60}\left(\frac{\Delta w}{\Delta t}\right)_{\max }^{2}}\right]$

$\eta_{i}=10 \times \log _{10}\left[\frac{\sum_{k=1}^{60}\left(\sum_{l=1}^{101} w_{\max }\right)^{2}}{\sum_{k=1}^{60}\left(\sum_{l=1}^{101} w\right)^{2}}\right]$,

$\eta_{i}=10 \times \log \left[W_{1} \times \frac{\sum_{k=1}^{60}\left(\mu_{\frac{\Delta w}{\Delta t}}\right)^{2}}{\sum_{k=1}^{60}\left(\sigma_{\frac{\Delta w}{\Delta t}}\right)^{2}}+W_{2} \frac{\sum_{k=1}^{60}\left(\mu_{w}\right)^{2}}{\sum_{k=1}^{60}\left(\sigma_{w}\right)^{2}}\right] i=1 \sim 9$

The above equations possess the expected property. The target value of the cutting rate $\Delta w / \Delta t$ is the optimized value by the large expected property. The target value of the ingot slicing contourvariance $w$ is the optimized value by the small expected property and $\mu=\frac{1}{n} \sum_{i=1}^{n} y_{i}, \sigma^{2}=\frac{1}{n-1} \sum_{i=1}^{n}\left(y_{i}-\mu\right)^{2}$. In the equation, $\Delta w / \Delta t, w, y_{i}$ are the values of each experimental item, $\Delta w / \Delta t_{\max }, w_{\max }$ are the maximal values of all experiments.

\subsection{The Optimized Design Result of the Diamond Multi-Wire Sawing.}

The purpose of utilizing Taguchi experimental method is to find the influence of the quality properties (slicing rate, ingot slicing contour variance etc.) of work pieceonDMWSslicing by tuning wire saw parameters (control factors).

Table 1 Experiment control factor and level design

\begin{tabular}{|l|l|l|l|}
\hline Control Factor & \multicolumn{3}{ll}{ Level } \\
\hline & 1 & 2 & 3 \\
\hline Tension Force $(\mathrm{H}, \mathrm{N})$ & 20 & 23.5 & 27 \\
\hline Wire Speed $(\mathrm{U}, m / s)$ & 10 & 12.5 & 15 \\
\hline Cutting Force $(\mathrm{F}, \mathrm{N})$ & 2 & 3 & 4 \\
\hline Gap Width $(\mathrm{Dk}, \mu m)$ & 150 & 165 & 180 \\
\hline
\end{tabular}

\subsubsection{Simulation Verification of Taguchi Method for}

\section{Slicing Rate}

From Equation (4), we can get the mean value $\eta$ of the slicing rate. Thus, the optimized combination of thecontrol factors of the slicing rate is $\left(H_{3} U_{3} F_{2} D k_{1}\right)$ : Tension Force
$H=27 N$, Wire Speed $U=15 \mathrm{~m} / \mathrm{s}$, Cutting Force $F=3 N$. Gap Width $D k=150 \mu m$ After substituting into the slicing equation, we can get the optimized slicing rate $8.459 \times 10^{-6} \mathrm{~m} / \mathrm{s}$ 。

\subsubsection{Simulation Verification of Taguchi Method for Ingot Slicing Contour Variance}

From Equation (4), we can get the mean value $\eta$ of the ingot slicing contour variance. Thus, the optimized combination of the control factors of the ingot slicing contour variance is $\left(H_{3} U_{1} F_{1} D k_{3}\right)$. After substituting into the ingot slicing contour variance equation, we can get the optimized slicing contour variance $2.220 \times 10^{-5} \mathrm{~m}$

\subsubsection{Simulation Verification of Hybrid Taguchi}

\section{Method for Slicing Speed and Contour Variance}

From Equation (4), we can get the mean value $\eta$ of slicing rate and ingot slicing contour variance. The optimized control factor combination of slicing rate and contour variance can be found to be $\left(H_{3} U_{3} F_{3} D k_{1}\right)$.

Table 2 Mean value $\eta$ of each control factor level for hybrid Taguchi experiment

\begin{tabular}{|l|l|l|l|}
\hline \multirow{2}{*}{$\begin{array}{l}\text { Control } \\
\text { Factor }\end{array}$} & \multicolumn{4}{|l|}{ Level $(\eta)$} & \multicolumn{2}{l|}{} \\
\cline { 2 - 4 } & 1 & 2 & 3 \\
\hline $\mathrm{H}$ & -15.482 & -15.502 & -15.5017 \\
\hline $\mathrm{U}$ & -15.737 & -15.471 & -15.277 \\
\hline $\mathrm{F}$ & -15.890 & -15.486 & -15.109 \\
\hline $\mathrm{Dk}$ & -15.353 & -15.560 & -15.572 \\
\hline
\end{tabular}

\section{DMWSSYNCHRONOUS DYNAMIC}

\section{TRACKING}

Diamond multi-wire sawing control system can be divided into main spindle roller multi-wire speed control system, slicing rate control system, tension and wire bow angle control system. Among these control system, the first one needs to take care of synchronous dynamic tracking technology, in this paper, we try to focus on this issue to investigate.

\subsection{Multi-Wire Speed Control System Design}

Fig. 4 has shown the control block diagram of the main spindle roller multi wire speed control system. The design of the main spindle roller speed control system is to control the speed of wire feed. The desired speed is obtained from Taguchi experimental method. In the diagram, $v_{H d}$ is the desired wire feed speed. Through the PID controller and motor driver, the magnetic torque is generated. And then deduct the tension torque caused by the tension force which comes from the wire bow angle control system. Finally, we can get the actual wire speed $v_{H a}$ of the main spindle roller. 


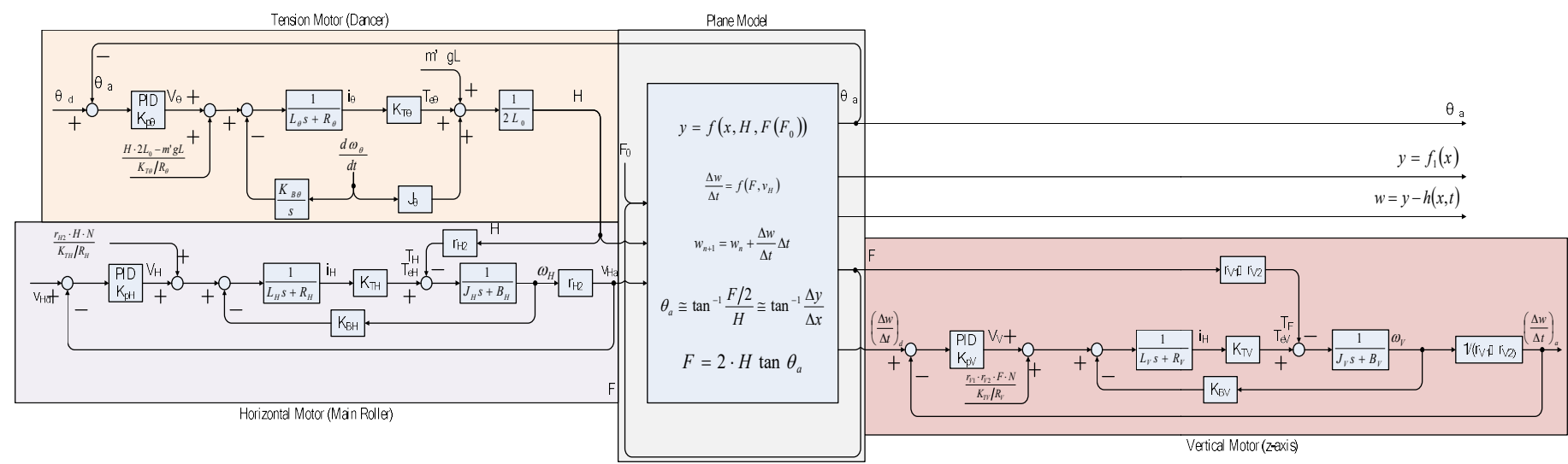

Fig.4 The block diagram of diamond multi-wire slicing dynamic system

\subsection{DMWS Synchronous Dynamic Tracking}

\section{Control}

The following isthe modelof the servo motor, input is the desired wire feed speed and output is the actual wire feed speed. $\mathrm{L}, \mathrm{R}$ is inductor and resistance of motor, $\mathrm{K}_{\mathrm{TH}}$ is the

constant of torque transform from current. J, Bismoment of inertia and rotational viscous friction coefficient. $\mathrm{R}_{\mathrm{H} 1}$ is coefficient of movement ratio from rotary to linear (main roller radius), $\mathrm{K}_{\mathrm{BH}}$ is back EMF constant.

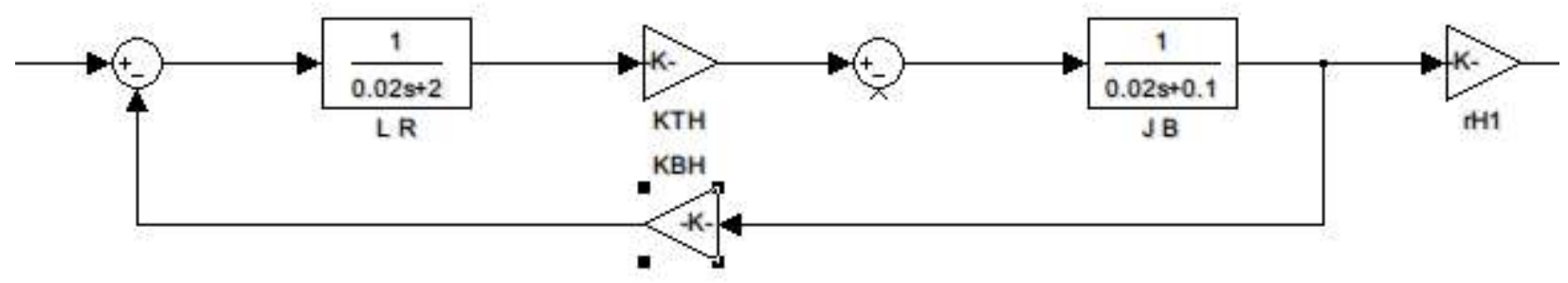

Fig.5 Motor Equivalent Model

Build 2 sets of servo motor system to simulate the actual situation with forward/reverse speed $10 \mathrm{~m} / \mathrm{s}$ and 1 sec cycle time. PID can be manually adjusted.

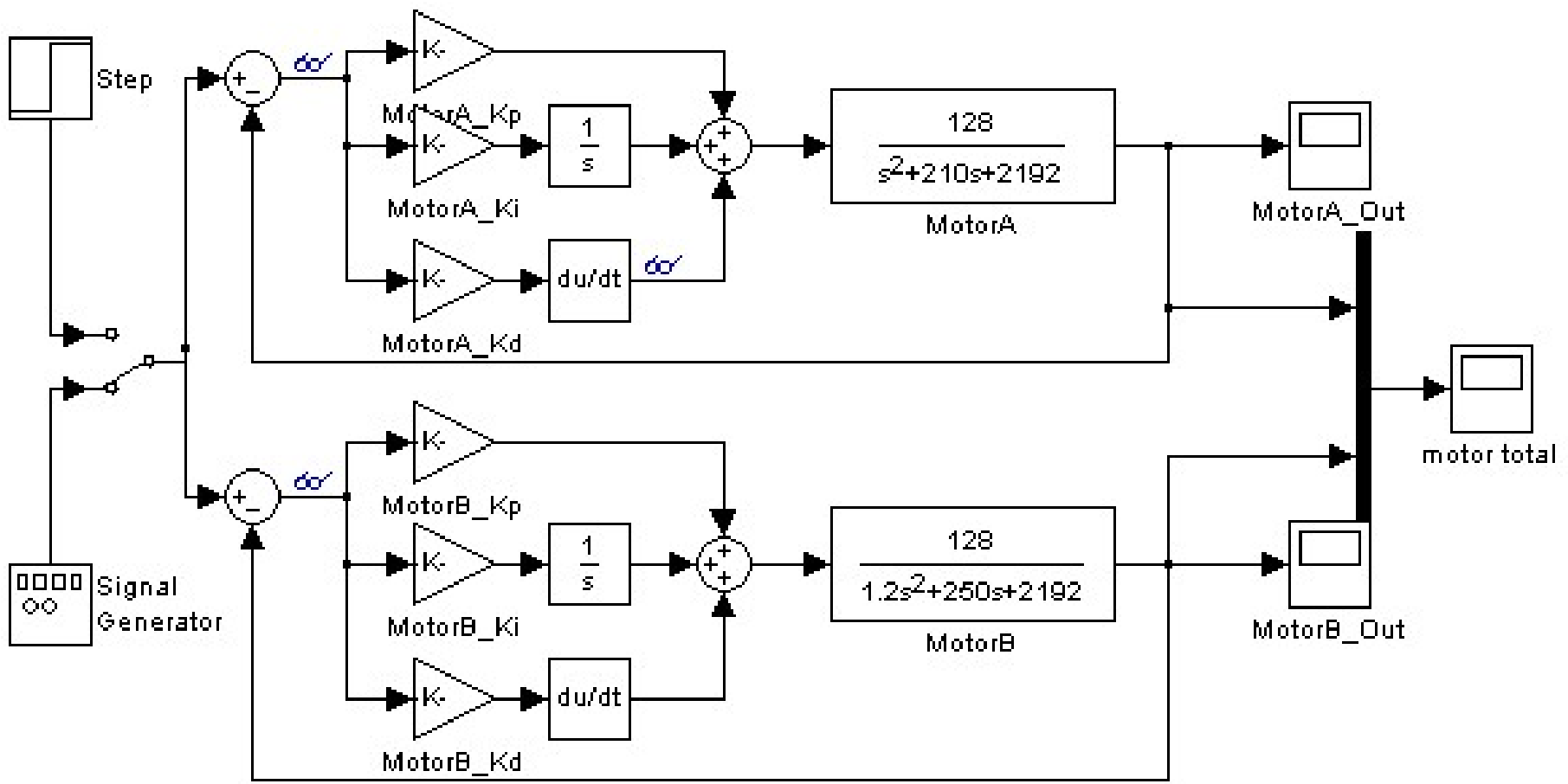

Fig.6 PID Controller Block Diagram 


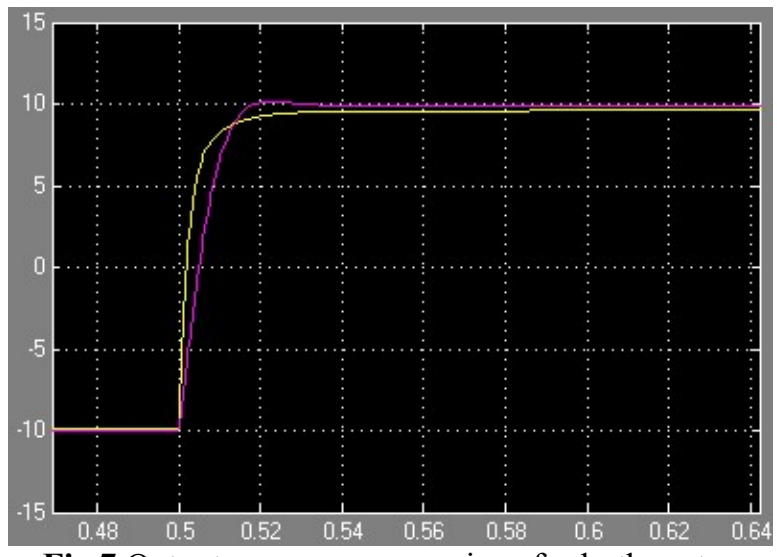

Using adaptive fuzzy-PID controller, we can improve the dynamic tracking performance for the 2 motors.In the following Fig.26, we use MotorA as reference end and MotorB as tracking end, andrun the tracking simulation by moving forward with $10 \mathrm{~m} / \mathrm{s}$ for $7 \mathrm{sec}$ and backward with $-10 \mathrm{~m} / \mathrm{s}$ for $5 \mathrm{sec}$.

Fig.7 Output response comparison for both motor systems(Yellow is MotorB, Purple is MotorA)
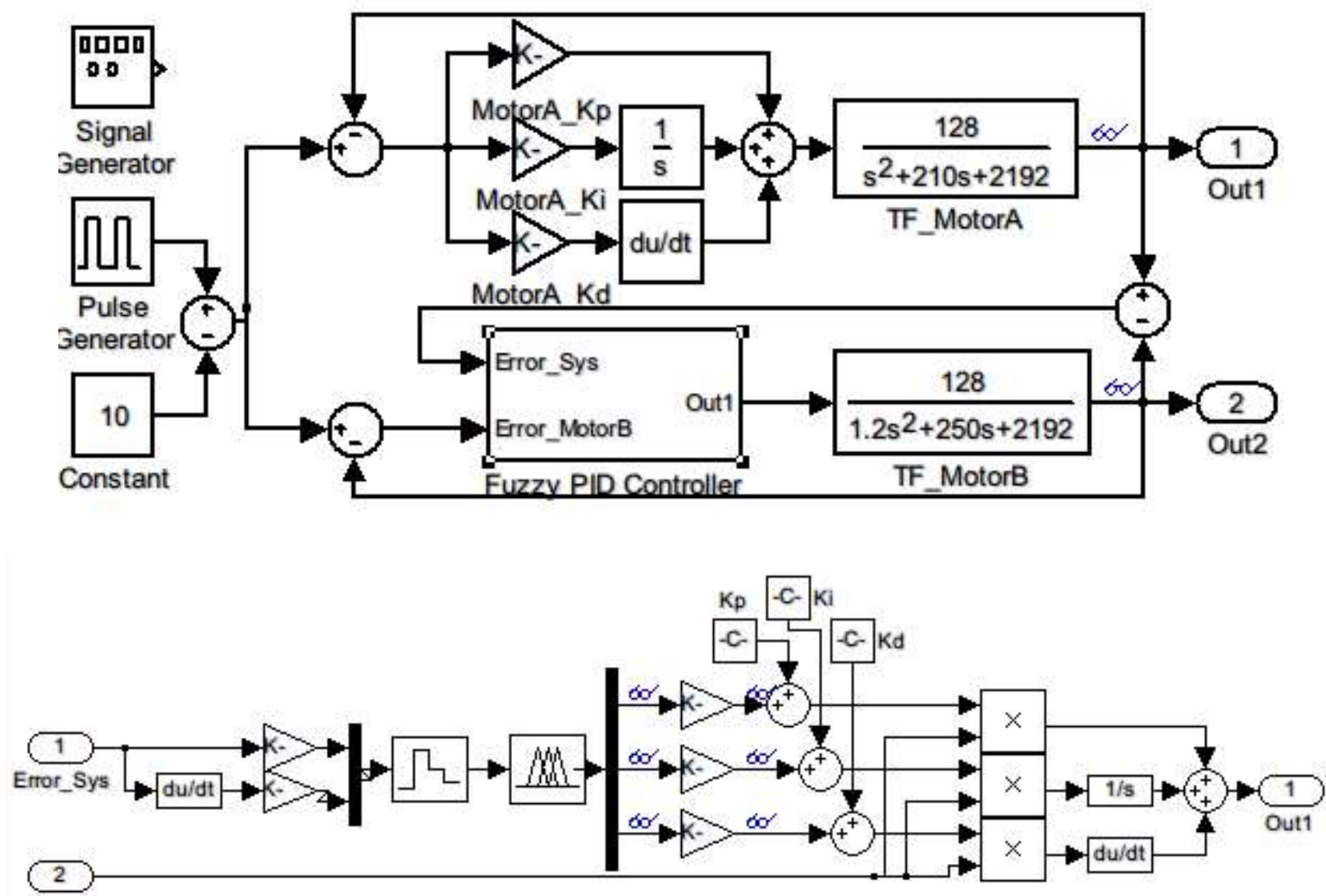

Emor_MotorB

Fig.8 Adaptive Fuzzy-PID Controller Block Diagram

Table 3 Fuzzy Rules

\begin{tabular}{|c|c|c|c|c|c|c|c|c|c|c|c|c|c|c|c|}
\hline \multicolumn{8}{|c|}{ fuzzy rule (kp) } & \multicolumn{8}{|c|}{ Fuzzy rule (ki) } \\
\hline \multirow[t]{2}{*}{ Error } & \multicolumn{7}{|c|}{ Derivative Error } & \multirow[t]{2}{*}{ Error } & \multicolumn{7}{|c|}{ Derivative Error } \\
\hline & NB & NM & NS & zo & PS & $\mathrm{PM}$ & PB & & NB & NM & NS & zo & PS & PM & PB \\
\hline NB & PB & PB & PM & PM & PS & $\mathrm{zo}$ & 20 & NB & NB & NB & NM & NM & NS & zo & 20 \\
\hline NM & PB & PB & PM & PS & PS & 20 & NS & NM & NB & NB & NM & NS & NS & zo & zo \\
\hline NS & PM & PM & PM & PS & zo & NS & NS & NS & NB & NM & NS & NS & 20 & PS & PS \\
\hline 20 & PM & PM & PS & zo & NS & $\mathrm{NM}$ & NM & zo & NM & NM & NS & zo & PS & PM & PM \\
\hline PS & PS & PS & zo & NS & NS & NM & NM & PS & NM & NS & 20 & PS & PS & PM & PB \\
\hline PM & PS & $\mathrm{zO}$ & NS & NM & NM & NM & NB & PM & zo & zo & PS & PS & PM & PB & PB \\
\hline PB & 20 & zo & NM & NM & NM & NB & NB & PB & $\mathrm{zO}$ & zo & PS & PM & PM & PB & PB \\
\hline
\end{tabular}

fuzzy rule (kd)

\begin{tabular}{|l|l|l|l|l|l|l|l|}
\hline \multirow{2}{*}{ Error } & \multicolumn{6}{|c|}{ Derivative Error } \\
\cline { 2 - 7 } & NB & NM & NS & ZO & PS & PM & PB \\
\hline NB & PS & NS & NB & NB & NB & NM & NS \\
\hline NM & PS & NS & NB & NM & NM & NS & ZO \\
\hline NS & ZO & NS & NM & NM & NS & NS & ZO \\
\hline ZO & ZO & NS & NM & NM & NS & NS & ZO \\
\hline PS & ZO & ZO & ZO & ZO & ZO & ZO & ZO \\
\hline PM & PB & PS & PS & PS & PS & PS & PB \\
\hline PB & PB & PM & PM & PM & PS & PS & PB \\
\hline
\end{tabular}




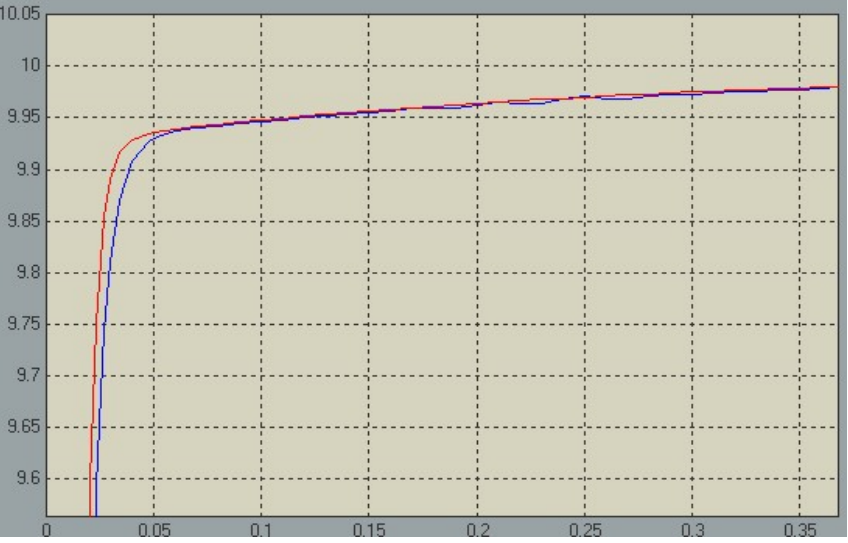

Fig.9 Adaptive Fuzzy-PID Control Response Diagram (Blue for Motor B, Red for Motor A)

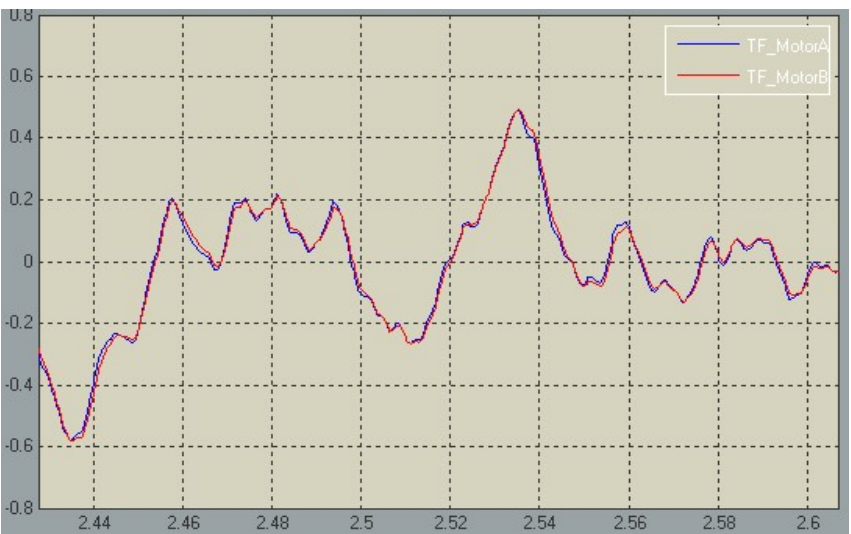

Fig.10 Adaptive Fuzzy-PID Control Diagram with High Frequency Signal

From the simulation result, we can discover the Fuzzy-PID control can increase the response speed to reach better tracking efficiency with little oscillation situation occurred while steady state.

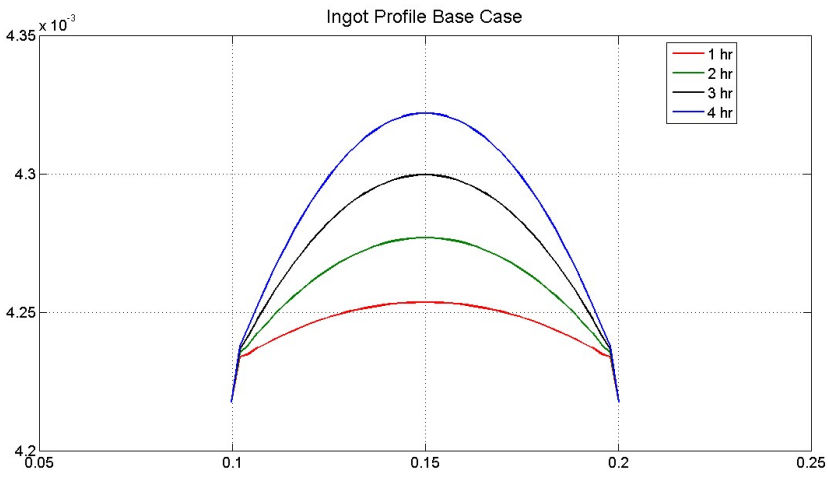

Fig.11 Slicing Dynamic Profile Diagram

\section{SIMULATION AND VERIFICATION}

\subsection{The Simulation and Verification of the Diamond}

\section{Multi Wire Slicing System Dynamic Model}

\subsubsection{Literatures Comparison}

The Slicing system portion refers to the literature [6], Table 4 is the parameters table used. The practical simulation result will compare with the result of literature [6]

Table 4 Parameter Table for literature comparison

\begin{tabular}{|l|l|l|}
\hline Parameter & Value & Unit \\
\hline H(tension) & 20 & $\mathrm{~N}$ \\
\hline U(wire velocity) & 10 & $\mathrm{~m} / \mathrm{s}$ \\
\hline E(wire elastic modulus) & 195 & $\mathrm{GPa}$ \\
\hline R(wire radius) & 80 & $\mu \mathrm{m}$ \\
\hline F(cutting force) & 1.7 & N/wire \\
\hline A(ingot area) & $100 \times 100$ & $\mathrm{~mm} 2$ \\
\hline L(spool to spool length) & 300 & $\mathrm{~mm}$ \\
\hline T(cutting time) & 4.3 & hour \\
\hline
\end{tabular}

System dynamic slicing profile as following Fig.11 and Fig.12, are for the comparison about the profile results for different timing. Therefore fix the both ends to the same point in order to see clearly the difference from different timing and the surface shape of the ingot is closer to the curvature of the wire or not. According to the simulation of MATLAB, the simulation result is similar to the literature result and if the slicing time is longer the slope of middle portion become steeper.

Fig.13 and Fig.14 are slicing rate comparison diagram for 1 hour and 4 hours. From overall view, we can observe the slicing rate for the both ends are larger and for the middle portion the slicing rate is smaller. And compare the situation between 1 hour and 4 hours can discover slicing rate for both ends reduce for 4 hours and increase for middle portion. This means the slicing rate gradually tend to be constant following with the time varying.

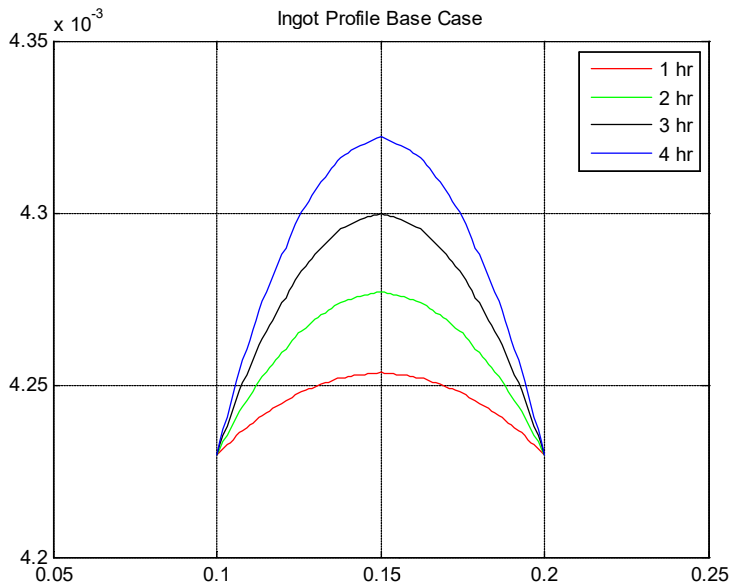

Fig.12 Slicing Dynamic Profile Simulation Result Diagram 


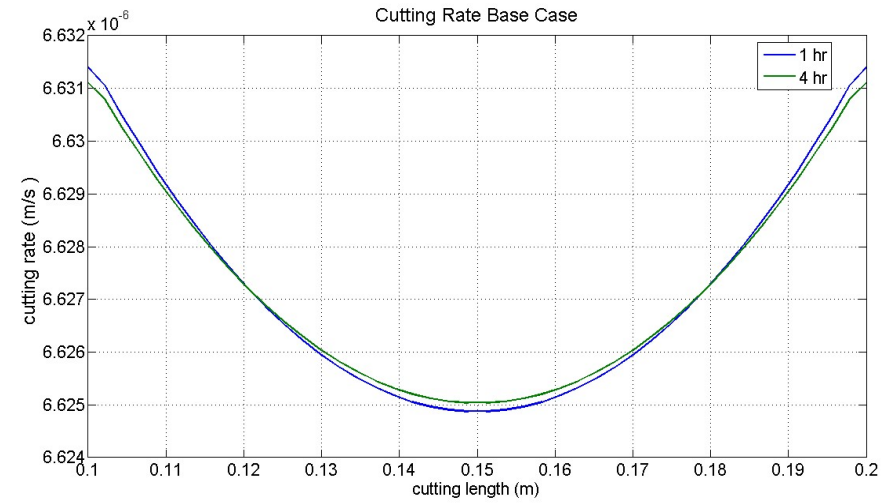

Fig.13 Slicing Rate Comparison Diagram

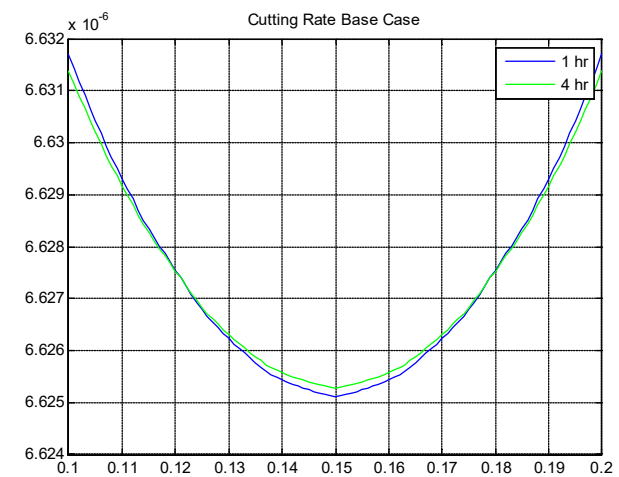

Fig.14 Slicing Rate Simulation Result Diagram

\subsubsection{Practical System}

According above comparison can verify the program written is reasonable and correct. Therefore we specify the practical system parameters into the program to execute and check if the result is reasonable. Table 5lists the parameters from practical system. The cutting force is specified while slicing wire angle to be $5.7^{\circ}$

Table 5 Practical System Parameters Table

\begin{tabular}{|l|l|l|}
\hline Parameter & Value & Unit \\
\hline $\mathrm{H}$ (tension) & 20 & $\mathrm{~N}$ \\
\hline $\mathrm{U}$ (wire velocity) & 15 & $\mathrm{~m} / \mathrm{s}$ \\
\hline $\mathrm{E}$ (wire elastic modulus) & 210 & $\mathrm{GPa}$ \\
\hline $\mathrm{E}_{\text {substrate }}$ (ingot elastic modulus) & 170 & $\mathrm{GPa}$ \\
\hline $\mathrm{R}$ (wire radius) & 60 & $\mu \mathrm{m}$ \\
\hline $\mathrm{F}$ (cutting force) & 4 & $\mathrm{~N} /$ wire \\
\hline $\mathrm{A}$ (ingot area) & $156 \times 156$ & $\mathrm{~mm} 2$ \\
\hline $\mathrm{L}$ (spool to spool length) & 620 & $\mathrm{~mm}$ \\
\hline $\mathrm{T}$ (cutting time) & 6 & $\mathrm{hr}$ \\
\hline $\mathrm{D}_{\mathrm{k}}$ (kerf width) & 165 & $\mu \mathrm{m}$ \\
\hline
\end{tabular}

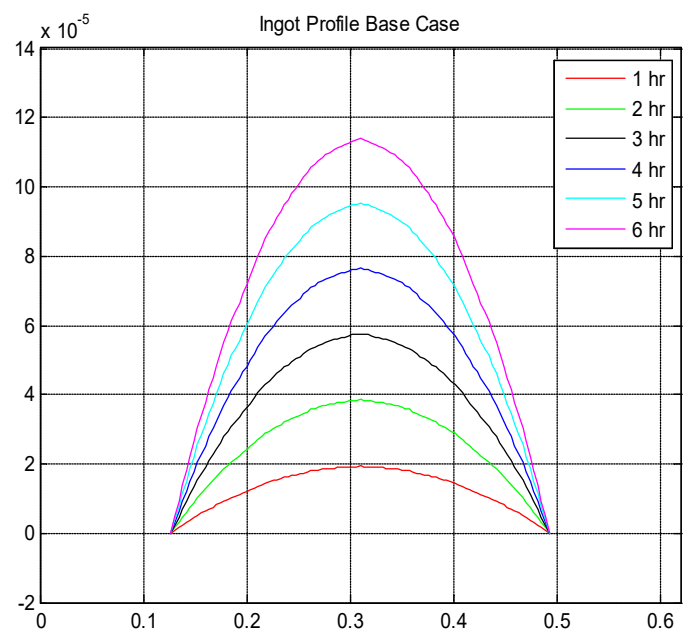

Fig.16 Slicing Dynamic Profile Simulation Result- Practical Parameters
From the front view of the system, we can see the real system is actually slicing 2 ingots at the same time but not only 1 ingot as Fig.15. The simulation trend is very similar to the above conclusion. We also adjust the simulation to 2 ingots slicing and the results as Fig.16 and Fig. 17.

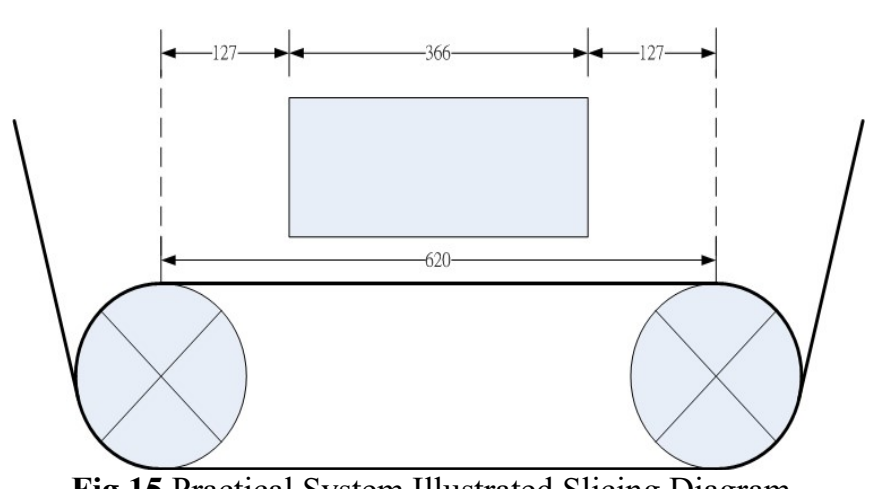

Fig.15 Practical System Illustrated Slicing Diagram

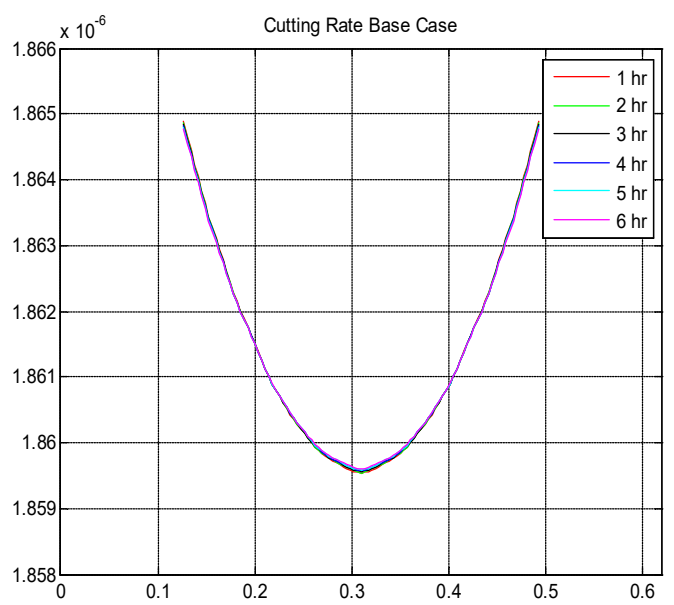

Fig.17 Slicing Rate Simulation Result-Practical Parameters 


\subsection{The Simulation and Verification of Diamond}

\section{Multi-Wire Slicing Control System}

\subsubsection{Simulation Framework}

For the slicing dynamic equation derivation, assume the wire feed to be single direction which is different from the real operation is reciprocating motion. Although the direction is different during the reciprocating motion, the system designed with the symmetry and the profiles are very similar. In order to simplify the dynamic equation, we make the value as absolute value to let input tension and linear velocity to be positive value.

\subsubsection{Multi-Wired Main Rollers Speed Control} System

Table 6 Practical Parameters of Multi-Wired Main Roller

\begin{tabular}{|l|l|l|}
\hline Parameter & Value & Unit \\
\hline $\mathrm{L}_{\mathrm{H}}$ & 0.02 & $\mathrm{H}$ \\
\hline $\mathrm{R}_{\mathrm{H}}$ & 2 & $\Omega$ \\
\hline $\mathrm{J}_{\mathrm{H}}$ & 0.360708 & $\mathrm{~kg} \cdot \mathrm{m} 2$ \\
\hline $\mathrm{B}_{\mathrm{H}}$ & 18.3054 & $\mathrm{~kg} \cdot \mathrm{m} 2 / \mathrm{sec}$ \\
\hline $\mathrm{r}_{\mathrm{H} 2}$ & 0.1 & $\mathrm{~m}$ \\
\hline
\end{tabular}

Table 6 is the parameter table of multi-wired main roller for Simulink simulation, the block diagram is shown in Fig.18. When the wire is running the reciprocating motion, the wire speed and tension is periodic changing as well. The modification of multi-wired main roller speed control is simpler and just to modify the input linear velocity to periodic motion.

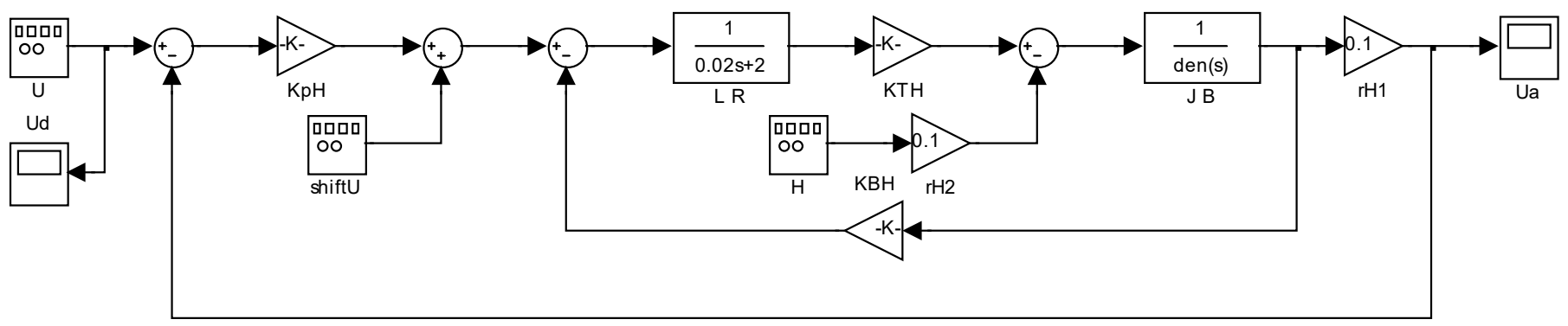

Fig.18 Simulink Simulation Diagram of Multi-Wired Main Roller Speed Control System

\subsection{The Performance Evaluation of Diamond}

\section{Multi-Wire Slicing System}

Using the above optimal slicing control and synchronous dynamic tracking design and simulation, we have the following conclusions:

(1). Given the tension force $\mathrm{H}(20 \mathrm{~N} \sim 28 \mathrm{~N})$ of moving wire, the simulation result shows that if thetension force increases, then wire deflection degree decreases, this conducts the cutting rate decreases at ingot two terminals and increases at the center of ingot. Therefore, the contour deflection degree tends to smoothness.

(2). Given the wire speed $U(10 \mathrm{~m} / \mathrm{s} \sim 15 \mathrm{~m} / \mathrm{s})$, the simulation result shows that if the wire speed increases $20 \%$, then cutting rate increases $20 \%$, that is to say the cutting time decreases to $83 \%$, but the ingot contourdeflection degree increases.

(3). In order to shorten the ingot cutting time, it is necessary to increase wire speed and vertical cutting force. Given the wire tension force $\mathrm{H}$, if we increase vertical cutting force, then the moving wire bow angle will enlarge; In the meanwhile, increase wire speed, also enlarge the ingot contour deflection degree. Therefore, we need to find an optimal balancing point.

(4). In addition, we can also decrease the moving wire radius $\mathrm{R}$ or Young's coefficient of ingot to increase the ingot cutting rate. But the radius of moving wire is too small, the wire breaks easily. So we need to take a trade-off.

(5). Bow angle of moving wire can be calculated from the horizontal wire tension force $\mathrm{H}$ and the vertical cutting force F.

(6). From the basic ablation theorem, the cutting rate is proportional to the vertical cutting force $\mathrm{F}$, horizontal moving wire speed $U$ and moving wire tension force $H$. Also, increase wire tension force can sustain less wire deflection degree.

(7). Cutting rate is larger, the surface roughness is worse. Also, abrasive particle is larger, the surface roughness is worse.

Based on the above conclusions, we take a summary with a simple table as follows: Where $\uparrow$ means increase, $\downarrow$ means decrease. 


\begin{tabular}{|l|l|l|l|l|l|l|l|l|}
\hline & $\mathrm{H} \uparrow$ & $\mathrm{U} \uparrow$ & $\mathrm{F} \uparrow$ & $\mathrm{R} \uparrow$ & $\begin{array}{l}E_{\text {substrate }} \\
\uparrow\end{array}$ & $\mathrm{E} \uparrow$ & $\begin{array}{l}\text { Cutting Rate } \\
\uparrow\end{array}$ & $\begin{array}{l}\text { Abrasive } \\
\text { Particle } \uparrow\end{array}$ \\
\hline Cutting Rate & & $\uparrow$ & $\uparrow$ & $\downarrow$ & $\downarrow$ & & & $\uparrow$ \\
\hline Ingot Contour Variance & $\downarrow$ & $\uparrow$ & $\uparrow$ & $\downarrow$ & & $\downarrow$ & & \\
\hline Surface Roughness $R_{a}$ & & $\downarrow$ & & & & & $\uparrow$ & $\uparrow$ \\
\hline Wear of Wire Saw & & $\uparrow$ & & & & & $\uparrow$ & \\
\hline
\end{tabular}

\section{CONCLUSION}

The simulation result shows that the optimal combinations for small ingot profile variance are high tension force, low wire velocity, and small cutting force. The cutting rate is direct proportional to moving wire speed and cutting force.

This DMWS slicing system demonstrates the wire bow angle of the multi-wire cutting system can be sustained to the desired angle within $5.7^{\circ}$, to proceed the stable control of the high-speed moving wire and stable cutting rate of multi-wire sawing in 7 forward and 5 backward motion.

\section{ACKNOWLEDGEMENT}

This research was sponsored by A-TECH System Co., Ltd. and National Science Council, Taiwan, R.O.C. under the grant NSC 99-2622-E-035-011-CC3and NSC 102-2218-E-005-012.

\section{REFERENCES}

[1]. Thomas Palathra, Raymond Adomaitis, "Process Modeling of a Wire Saw Operation," The Institute for Systems Research, 2008

[2]. W.I. Clark, A.J. Shih, C.W. Hardin, R.L. Lemaster and S.B. McSpadden, " FixedAbrasiveDiamond Wire Machining - part I: Process Monitoring and Wire Tension Force," International Journal of Machine Tools \& Manufacture, 2003

[3]. William I. Clark, Albert J. Shih, Richard L. Lemaster and Samuel B. McSpadden, " Fixed Abrasive Diamond Wire Machining_part II: Experiment Design and Results," International Journal of Machine Tools \& Manufacture, 2003

[4]. Zhang Yibing, Dai Yuxing, Yuan Julong and XiongWanli, "Design and Implement of Wire Tension Control System for Multi-Wire Saw," Journal of Mechanical Engineering, 2009

[5]. Madhav S. Phadke "“Quality Engineering Using Robust Design",PrenticeHall,Englewood Cliffs, 1989.

[6]. Thomas Palathra, Raymond Adomaitis, "Process Modeling of a Wire Saw Operation,"The Institute for Systems Research, 2008

[7]. Thomas Palathra, Raymond Adomaitis,"Process Modeling of a Wire Saw Operation,"The Institute for Systems Research, 2008 